\title{
The Association of Health and Employment in Mature Women: A Longitudinal Study
}

\author{
Sabrina W. Pit, Ph.D., M.S.c., and Julie Byles, Ph.D., BMed²
}

\begin{abstract}
Background: Despite a reduction in income inequalities between men and women, there is still a large gap between income and retirement savings of Australian men and women. This is especially true for women who have health or disability problems. Mature age women are closest to retirement and, therefore, have less chance than younger women to build up enough retirement savings and may need to continue working to fund their older age. Continued workforce participation may be particularly difficult for women who are less healthy. Understanding which health problems lead to a decrease in workforce participation among mature age women is crucial. Therefore, this longitudinal study sought to identify which health problems are associated with employment among midage women over time.

Methods: Data were analyzed from the midage cohort of the Australian Longitudinal Study on Women's Health (ALSWH), which involved 14,200 midage women (aged 45-50 years in 1996). The women have been surveyed four additional times, in 1998, 2001, 2004, and 2007. Generalized estimating equations (GEE) were used to conduct nested multivariate longitudinal analyses.

Results: The percentages of women who were employed in the years 2001, 2004, and 2007 were 77\%, 72\%, and $68 \%$, respectively. Results were adjusted for sociodemographic variables. Being employed decreased as physical and mental health deteriorated and with self-reported conditions: diabetes, high blood pressure, depression, anxiety, and other psychiatric conditions. Back pain, arthritis, cancer, obesity, and being a current smoker are associated with employment but not when quality of life is added to the model.

Conclusions: There were significant associations between health and employment. Understanding these relationships could inform policies and guidelines for preventing declines in employment in mature age women.
\end{abstract}

\section{Introduction}

A S POPULATIONS AGE, MANY GOVERNMENTS are encouraging older people to maintain or increase their workforce participation and to remain working until older ages. The reasons for this policy are manyfold and include the need for older workers to fill positions where workforce is scarce, broadening the base of taxpayers, and reducing dependency on government pensions. Older people often choose to work because they wish to maintain participation in the paid workforce or because they have not yet established sufficient financial savings to retire. Major reasons people give for decisions to retire include personal health and income security. ${ }^{1,2}$

Despite a reduction in income inequalities between men and women, there is still a large gap between retirement savings of Australian men and women. ${ }^{3}$ Mean retirement savings are lower for women. ${ }^{4}$ In most countries, a comfortable retirement is dependent entirely on occupational history, which disadvantages women, who are more likely to have a fragmented career. ${ }^{4}$ This is especially true for women who have health or disability problems. Australian women aged 45-54 with "limited abilities" have on average only AU\$ 31,105 in retirement savings, whereas women without such limitations have on average AU\$ $82,957 .{ }^{5}$ Mature age women are closest to retirement and, therefore, have less chance than younger women to build up enough retirement savings. Hence, it is imperative to increase retirement savings for this age category, particularly among women who are less healthy. To do this, understanding which health problems lead to a decrease in workforce participation among mature age women is crucial and is the aim of this article.

Health problems can be seen as a push factor into early retirement among women ${ }^{6}$ and can affect employment in several ways. For example, health problems, such as obesity, can reduce people's mental or physical health and thereby reduce their ability to take part in employment. ${ }^{7}$ The impact of

\footnotetext{
${ }^{1}$ University Centre for Rural Health, Northern Rivers School of Public Health, University of Sydney, Australia.

${ }^{2}$ Research Centre for Gender, Health and Ageing, University of Newcastle, Australia.
} 
health on employment outcomes will vary by disease and individual circumstances. ${ }^{8}$ For example, an Australian study found that $40 \%$ of women who have been diagnosed with colorectal cancer were not working 1 year after diagnosis ${ }^{9}$ and that chemotherapy had a negative impact and health insurance a protective effect on work status. It needs to be acknowledged that the context of employment is very complicated and is influenced by a multitude of factors other than health, such as labor market conditions, ${ }^{7}$ financial retirement incentives, caring status, ${ }^{10}$ and working conditions, and that these factors interact with health. The House of Work Ability, developed by the Finnish Institute of Occupational Health, is a widely used approach to conceptualize the complexity of work and promote aging in the workplace. ${ }^{11}$ Briefly, the House consists of four floors that interconnect the concepts of a personal dimension (health and functional capacities, competence, values, attitudes and motivation) and a work dimension (conditions, content and demands, community and organization, and leadership). The House is also influenced by external factors, such as family, the external operational environment, and societal factors. ${ }^{11}$ Our study focuses mainly on the impact of health problems on employment status and quantifies the relationship with employment for various health problems.

\section{Health problems, workforce participation, and longitudinal analysis}

Many studies examining health problems and employment have been cross-sectional in design. ${ }^{12-14}$ Longitudinal analysis can determine the change over time of an outcome variable in relation to change over time of other variables. Also, whereas cross-sectional studies can measure only betweenindividual differences in outcome variables, longitudinal studies can also measure within-individual differences. ${ }^{15}$ There are studies of health and retirement that have been longitudinal in design, including longitudinal analysis among civil servants ${ }^{16}$ and Dutch older workers, ${ }^{17}$ and specific health problems, such as diabetes ${ }^{18}$ and overweight or obesity. ${ }^{19}$

There are several international longitudinal studies in various stages of progress investigating the relationship between aging and health, such as the US Health and Retirement Survey (HRS), the English Longitudinal Survey of Ageing (ELSA), the European Survey of Health and Retirement Economics (SHARE), the China Health and Retirement Longitudinal Study (CHARLS), and the Longitudinal Ageing Study in India (LASI). ${ }^{20}$ The Canadian Longitudinal Study on Aging (CLSA) started recruitment in 2009. In Australia, the Household, Income and Labour Dynamics (HILDA) survey started in 2001 and surveys over 19,000 individuals annually; it contains important information on health and workforce (www.melbourneinstitute.com/hilda). The Australian Longitudinal Study on Women's Health (ALSWH) started in 1996, is a nationally representative sample, and was specifically designed to understand women's health. Consequently, it has detailed health information that can be used to examine the relationship between health and workforce participation among mature age women.

To date, no longitudinal analysis has been conducted to determine which health problems impact workforce participation over time in a national representative sample of Australian women approaching retirement age. This current research aims to determine the health problems that are most associated with workforce participation, using data from a nationally representative sample, the midage cohort of the ALSWH.

\section{Material and Methods}

\section{Sample}

This research was conducted as part of the ALSWH, which was designed to investigate multiple factors affecting the health and well-being of women over a 20 -year period. Women aged 45-50 were randomly selected from the national Medicare database, with overrepresentation of women living in rural and remote areas. ${ }^{21}$ The focus of this study is women from the 1946-1951 birth cohort who have been surveyed five times over a 12-year period (1996-2007). The baseline survey, survey 1 (S1, $n=13,715)$, was conducted in 1996, when the women were aged 45-50 years. Respondents have been shown to be broadly representative of the national population of women in the target age groups. ${ }^{21}$ Survey $2(\mathrm{~S} 2, n=12,338)$ was conducted in 1999, survey 3 was conducted in 2002 (S3, $n=11,226)$, survey 4 was conducted in $2004(S 4, n=10,905)$, and survey 5 was completed in 2007 (S5, $n=10,638$ ), when the women were aged 56-61 years. The University of Newcastle Human Research Ethics Committee and The University of Queensland Medical Research Ethics Committee approved the Women's Health Australia Study.

\section{Measures of employment status}

Data were collected by self-report questionnaire (available at www.alswh.org.au). Women were asked: In the last week, how much time in total did you spend, doing the following things? If a woman reported spending 1 hour or more a week on full-time paid work, permanent part-time paid work, casual paid work, or work without pay (e.g., family busines), the woman was classified as being employed. Women who reported being employed were compared to women reporting not being in the labor force or unemployed.

\section{Measures of demographic characteristics}

Location was classified into two groups, urban and rural/ remote, according to the Rural Remote and Metropolitan Areas Index, which reflects distance from service centers and other people and is based on postal codes. ${ }^{22}$ Women were asked about their highest educational qualification, their current marital status, and any children living at home. Caring for a person because of their long-term illness, disability, or frailty was classified as No or Yes, someone who lives with you, and Yes, someone who lives elsewhere. The Relative Socioeconomic Disadvantage Index was used, which reflects general socioeconomic indicators that contain variables related to economic and social characteristics of families and households and education level and occupation of individuals. A higher score represents greater advantage. ${ }^{23}$

\section{Measures of health problems}

At each time point, women were asked: In the past 3 years, have you been diagnosed or treated for arthritis [asked from S3 onward], diabetes (high blood sugar), heart disease (including heart attack, angina), hypertension (high blood 
pressure), stroke, asthma, bronchitis/emphysema, osteoporosis, breast cancer, cervical cancer, other cancer (excluding skin or melanoma), depression, anxiety/nervous disorder, other psychiatric disorder, and chronic fatigue syndrome? We also included women who reported often having back pain in response to a question about symptoms experienced in the past 12 months because this symptom impacts greatly on people's employability. ${ }^{13}$ Analysis was limited to survey time points 3,4 , and 5 because arthritis was only measured from S3 onward, and previous research ${ }^{13}$ has demonstrated that arthritis has a large impact on people's ability to work, and to not include this variable in the model would distort the findings.

\section{Measures of lifestyle}

The smoking status of women was defined by their response to a question on the number of cigarettes they smoke per day. Body mass index (BMI) was calculated from selfreported height and weight and classified according to the BMI categories recommended by the World Health Organization (WHO) and is based on risk of comorbidities. ${ }^{24}$

\section{Measures of health status}

The Short-Form 36 (SF-36) Quality of Life questionnaire was used to create a measure of quality of life with eight dimensions (physical functioning, role limitation caused by physical factors, bodily pain, general health, vitality, social functioning, role limitation caused by social factors, and mental health). ${ }^{25}$ A physical component score (PCS) and a mental component score (MCS) were derived from the SF-36 and standardized against the American adult population. ${ }^{26}$

\section{Statistical analysis}

At each survey, demographic characteristics, health problems, lifestyle factors, and quality of life were compared for women who were employed and those who were not, using chi-square tests for categorical variables and $t$ tests for continuous variables (cross-sectional analyses). A $p$ value $<0.005$ was used for statistical significance because of the large sample size and multiple comparisons. The Relative Socioeconomic Disadvantage Index score distribution was categorized into quartiles to enable comparison over time. ${ }^{23}$

Generalized estimating equations (GEE) were used to conduct nested multivariate longitudinal analyses. All analyses were conducted using procedure GENMOD in the statistical program SAS 9.2. GEE can be used to deal with correlated discrete responses, such as longitudinal data. ${ }^{27}$ PROC GENMOD computes by default robust standard error (SE) estimates. These estimates take into account the correlations among the repeated measurements. An unstructured correlation matrix was used to adjust for the correlation between repeated measurements to take into account the longitudinal character of the data. The unstructured correlation matrix was chosen because we had a large number of subjects, with relatively few measurements per subject. ${ }^{27}$

Time was included in all models as a separate variable. ${ }^{27}$ We took the following steps in building the nested models for health problems, health problems plus lifestyle factors, and health problems, lifestyle factors, and health-related quality of life:
1. Univariate analyses were conducted to examine the relationship between employment and the explanatory variables at each time point. All variables that were statistically significant in the cross-sectional analyses were considered for model building (Table 1).

2. Basic model. Crude odds ratios (ORs) were estimated from GEEs for each variable before multivariate analysis. In building the adjusted multivariate models, time (survey) and area of residence were included in all models regardless of the results of univariate analyses. All sociodemographic variables that were statistically significant in the univariate logistic regression (GEE) were entered into a basic multivariate model. To reduce the number of categories, variables were dichotomized where possible. Least significant variables were removed from the model until only statistically significant variables remained. This model was used to further adjust each of the main models for analysis (models 1,2, and 3).

3. Model 1: Health problems. All health problems that were statistically significant on cross-sectional analyses were entered into model 1 and with adjustment for sociodemographic variables in the basic model. Least significant variables were removed from the model until only statistically significant variables remained.

4. Model 2: Health problems plus lifestyle factors. Obesity and smoking status were added to the model.

5. Model 3: Health problems, lifestyle factors, and healthrelated quality of life. In the final model, SF-36 PCS and MCS components scores were added.

Model diagnostics for GEE regression models were applied by using the GEE case deletion diagnostic statistics created in the procedure GENMOD in SAS 9.2 (SAS Institute). We examined the clusters (women) that exceeded the 99th percentile for the distribution of Cook's D for the cluster and the cluster lack of fit statistics. These outliers were examined and deleted from the final model to see if it changed the results. The Quasilikelihood Information Criteria (QIC) were used to compare the three different GEE models. The model with the smallest QIC value was chosen as the best model. ${ }^{27}$ Collinearity was assessed by examining the Condition Index of the included variables for each model and testing if SEs changed by deleting variables from the model.

Because back pain is well known to be a major driver of not being able to work ${ }^{13}$ and had a high number of missing values at S3, we imputed values for back pain at S3 by using a method similar to last value carried forward. For example, if a woman had the same code for back pain at S2 and S4 but was missing a value for S3, she was allocated the same code at S3. A sensitivity analysis was carried out to determine if using this method led to similar results found with models that did not impute data for missing values on this variable.

\section{Results}

Across the three survey periods, the percentage of women who participated in each survey and who were employed in 2001, 2004, and 2007 were $77 \%, 72 \%$, and $67 \%$, respectively. However, attrition between surveys was associated with employment status, indicating an increasing bias toward women who were more likely to be employed at each survey $(p<0.0001$ on chi-square analysis). Among women who did 
not respond to S3, 77.4\% were employed in paid work at S1, compared with $83.6 \%$ for those who responded to S3. Corresponding figures for women responding to subsequent surveys were $73.9 \%$ vs. $81.8 \%$ (S4) and 71.4 vs. $80.1 \%$ (S5).

\section{Cross-sectional analysis}

Table 1 shows cross-sectional comparisons of women who were and who were not employed, for the sociodemographic, health problems, lifestyle, and health status characteristics for the three survey periods.

Sociodemographics. There were no statistically significant differences between employed and nonemployed women in terms of area of residence or baseline age. For all three surveys, women who were not employed were more likely to be married or in a de facto relationship, and women who were employed were more likely to be divorced or separated. A significantly higher proportion of employed women reported having children at home (S4 and S5 only). Table cell contributions to the total Pearson chi-square statistic showed that women who were not employed were significantly more likely to be providing care for someone living with them. Women who were employed had significantly higher Relative Socioeconomic Disadvantage Indexes.

Health problems. At each survey, women who were not in paid employment were more likely to report the health problems listed in Table 1 compared with women in paid employment, except for stroke and cancer (S3 and S5).

Lifestyle. Compared with employed women, women who were not employed were significantly more likely to have a BMI in the obese range and were also more likely to smoke (S3 and S4 only).

Quality of life. Compared with employed women, women who were not employed had lower MCS and PCS scores at each survey. Over time, the proportion of married women declined, whereas the proportion of divorced and widowed women increased. The proportion of women with children at home also declined, and the majority of the health problems increased in proportion or stayed the same. Women's MCS scores increased over time, whereas their PCS scores remained the same.

\section{Longitudinal analysis}

Time. The odds of a woman being employed decrease with time. In the final model (Table 2, model 3), in comparison to S3 (aged 50-55), the ORs for S4 (aged 53-58) were 0.74 (95\% confidence interval [CI] 0.69-0.80 and for S5 (aged 56-61) 0.60 (95\% CI 0.56-0.65).

Basic model. Sociodemographic factors listed in Table 1 were initially all entered into a longitudinal multivariate model, and after stepwise elimination, the following variables remained in the model: education (high school Certificate or lower vs. degree/trade: crude OR $0.46,95 \%$ confidence interval [CI] 0.42-0.52), area of residence (urban vs. remote: crude OR $1.03,95 \%$ CI 0.94-1.14), marital status (separated/divorced/ single vs. married/de facto / widowed: crude OR 0.90, 95\% CI: 0.80-1.00), caring for someone the woman lives with vs. a woman who does not (crude OR 0.76, 95\% CI 0.72-0.81), and Relative Socioeconomic Disadvantage Index (quartiles 1 and 2 vs. quartiles 3 and 4: crude OR 1.21, 95\% CI 1.13-1.30). These variables were used to adjust the main models. The variable, children at home, was no longer associated with employment once other factors were included in the basic model.

Model 1. All 14 health problems were associated with being less likely to be employed (Table 1) and were entered into model 1. After stepwise elimination, 8 health problems remained in the model (Table 2, model 1). ORs attenuated after adjusting for sociodemographic variables when compared to the crude ORs (Table 2). Sensitivity analyses to test if imputation of missing values for back pain made a difference to the model showed no substantive differences in ORs or significance levels.

Model 2. Obesity and smoking were associated with employment status (Table 2, model 2). ORs for the 8 health problems did not change much after these two lifestyle factors were entered.

Model 3. When quality of life was entered into the model (Table 2, model 3), only 5 health problems remained significantly associated with employment status. Women who reported psychiatric conditions, diabetes, depression, anxiety, and high blood pressure were less likely to be employed. In terms of the SF-36 PCS, for every 10 point increase, women are 1.35 (95\% CI 1.29-1.44) times more likely to be employed. In terms of the SF-36 MCS, for every 10 point increase, women are 1.09 (95\% CI 1.05-1.14) times more likely to be employed. Effects of diagnoses that remain after adding MCS and PCS quality of life scores are important beyond the effects on quality of life associated with the condition. The health problems and lifestyle factors that are no longer associated with employment (back pain, arthritis, cancer, bronchitis, obesity, and smoking) are explained through their impact on the woman's quality of life.

In comparison to the unadjusted OR, the adjusted OR for mental health did not change when it was adjusted for health conditions, obesity, and smoking, whereas the adjusted OR for the physical health score decreased.

Clusters of women who exceeded the 99th percentile for the distribution of Cook's D for the cluster and the cluster lack of fit statistics were classified as outliers (272 outliers) and were further examined and deleted from the final model, with no effect on the results. QIC indicates that model 3 has the best fit (Table 2). No collineairity was found by examining the Condition Index and the Variance Inflation Factors of the included variables. Additionally, SEs did not change much by deleting variables from the model and did not change the interpretation of the models, suggesting that collinearity was not an issue in the models.

\section{Discussion}

This study indicates that older women's workforce participation is affected by demographic and health factors. Health factors associated with women's employment status included a number of reported conditions as well as health risk behaviors and quality of life. Five conditions had a major association with employment while controlling for other important variables. From a socioeconomic point of view and similar to our study, other studies have also found that women with lower education, ${ }^{8}$ socioeconomic disadvantage, being separated, divorced, or single ${ }^{8,12,28}$ and having caring responsibilities for people living in the same house ${ }^{10}$ were less likely to be employed. 
Table 1. Demographics, Health Problems, Lifestyle, and Quality of Life of Midage Australian Women by Employment Status

\begin{tabular}{|c|c|c|c|c|c|c|}
\hline \multirow[b]{3}{*}{ Characteristic } & \multirow{2}{*}{\multicolumn{2}{|c|}{$\frac{\text { Survey } 32001}{\text { Employed }}$}} & \multirow{2}{*}{\multicolumn{2}{|c|}{$\begin{array}{c}\text { Survey } 42004 \\
\text { Employed }\end{array}$}} & \multirow{2}{*}{\multicolumn{2}{|c|}{$\begin{array}{c}\text { Survey } 52007 \\
\text { Employed }\end{array}$}} \\
\hline & & & & & & \\
\hline & $\begin{array}{c}\text { No } \\
\mathrm{n}=2,554 \\
\%\end{array}$ & $\begin{array}{c}\text { Yes } \\
\mathrm{n}=11,148 \\
\%\end{array}$ & $\begin{array}{c}\text { No } \\
\mathrm{n}=3,058 \\
\% \\
\%\end{array}$ & $\begin{array}{c}\text { Yes } \\
\mathrm{n}=7,763 \\
\%\end{array}$ & $\begin{array}{c}\text { No } \\
\mathrm{n}=3,437 \\
\%\end{array}$ & $\begin{array}{c}\text { Yes } \\
\mathrm{n}=7,112 \\
\%\end{array}$ \\
\hline \multicolumn{7}{|l|}{ Sociodemographics } \\
\hline \multicolumn{7}{|l|}{ Education ${ }^{*, * *, * * *}$} \\
\hline No formal & 25 & 12 & - & - & - & - \\
\hline $\mathrm{SC} / \mathrm{HSC}$ & 52 & 48 & - & - & - & - \\
\hline Trade/Ap/Cert/Dip & 17 & 22 & - & - & - & - \\
\hline$\geq$ University & 6 & 18 & - & - & - & - \\
\hline \multicolumn{7}{|l|}{ Area of residence } \\
\hline Remote & 63 & 63 & 63 & 61 & 61 & 60 \\
\hline Urban & 37 & 37 & 37 & 39 & 39 & 40 \\
\hline \multicolumn{7}{|l|}{ Marital status $s^{*, * * * * * *}$} \\
\hline Married/de facto & 84 & 83 & 83 & 80 & 82 & 78 \\
\hline Widowed & 3 & 3 & 4 & 4 & 5 & 5 \\
\hline Separated/divorced & 10 & 11 & 10 & 14 & 11 & 14 \\
\hline Never married & 2 & 3 & 2 & 3 & 3 & 3 \\
\hline Children at home (yes) $)^{* * * * * *}$ & 35 & 39 & 25 & 29 & 16 & 21 \\
\hline \multicolumn{7}{|l|}{$\begin{array}{l}\text { Provides care for someone because of their } \\
\text { long-term illness, disability, or frailty }{ }^{*, * *, * * *}\end{array}$} \\
\hline No & 71 & 75 & 68 & 72 & 68 & 72 \\
\hline Yes, someone who lives with you & 11 & 5 & 12 & 6 & 12 & 6 \\
\hline Yes, someone who lives elsewhere & 17 & 20 & 19 & 22 & 20 & 22 \\
\hline \multicolumn{7}{|l|}{ SEIFA disadvantage $\mathrm{e}^{* * * * * * * *}$} \\
\hline Quartile 1 & 30 & 23 & 28 & 23 & 28 & 22 \\
\hline Quartile 2 & 25 & 24 & 28 & 24 & 26 & 25 \\
\hline Quartile 3 & 25 & 26 & 24 & 25 & 25 & 26 \\
\hline Quartile 4 & 20 & 26 & 20 & 28 & 22 & 28 \\
\hline \multicolumn{7}{|l|}{ Health problems } \\
\hline Arthritis ${ }^{*, * *, * * *}$ & 31 & 22 & 33 & 23 & 37 & 26 \\
\hline Diabetes ${ }^{*, * * * * * *}$ & 6 & 2 & 7 & 4 & 9 & 5 \\
\hline Heart disease $\mathrm{e}^{*, * *, * * *}$ & 3 & 1 & 5 & 2 & 6 & 3 \\
\hline High blood pressure ${ }^{*, * *, * * *}$ & 24 & 16 & 25 & 19 & 34 & 25 \\
\hline Stroke $e^{* * * * *}$ & 1 & 0 & 1 & 0 & 1 & 1 \\
\hline Asthma $a^{* * *, * * *}$ & 12 & 9 & 13 & 9 & 12 & 9 \\
\hline Bronchitis $^{*, * * * * * *}$ & 6 & 4 & 7 & 4 & 7 & 5 \\
\hline Osteoporosis ${ }^{* * * * * * *}$ & 5 & 3 & 7 & 5 & 7 & 6 \\
\hline Cancer ${ }^{* * * * *}$ & 4 & 3 & 4 & 3 & 5 & 3 \\
\hline Depression $*, * * * * * *$ & 17 & 10 & 16 & 11 & 16 & 11 \\
\hline Anxiety ${ }^{*, * * * * * *}$ & 10 & 6 & 11 & 7 & 13 & 8 \\
\hline Any other psychiatric condition ${ }^{* * * * * * * *}$ & 1 & 0 & 2 & 0 & 1 & 1 \\
\hline Chronic fatigue syndrome $e^{*, * *, * * *}$ & 2 & 1 & 2 & 1 & 2 & 1 \\
\hline Back pain $*, * *, * * * *$ & 28 & 18 & 23 & 15 & 26 & 16 \\
\hline \multicolumn{7}{|l|}{ Lifestyle } \\
\hline \multicolumn{7}{|l|}{ Smoking ${ }^{* * * *}$} \\
\hline Yes & 18 & 13 & 14 & 12 & 10 & 9 \\
\hline \multicolumn{7}{|l|}{ Weight ${ }^{*, * *, * * *}$} \\
\hline Body mass index $>30$ & 28 & 22 & 31 & 23 & 31 & 24 \\
\hline \multicolumn{7}{|l|}{ Quality of life: Mean (SD) } \\
\hline SF-36 Mental Health Component score ${ }^{*, * * * * * *}$ & $48(12)$ & $50(10)$ & $49(12)$ & $51(10)$ & $50(11)$ & $52(9)$ \\
\hline SF-36 Physical Health Component score ${ }^{*, * *, * * *}$ & $44(12)$ & $49(9)$ & $44(12)$ & $49(9)$ & $44(11)$ & $49(9)$ \\
\hline
\end{tabular}

*Significant association with workforce participation in survey $3(\mathrm{p}<0.005)$; ${ }^{* *}$ significant association with workforce participation in survey 4 ( $<<0.005) ;{ }^{* * *}$ significant association with workforce participation in survey $5(\mathrm{p}<0.005)$.

Ap, apprenticeship; Cert, certificate; Dip, diploma; HSC, higher school or leaving certificate; SC, school or intermediate certificate; SD, standard deviation; SEIFA, socio-economic indexes for areas. 


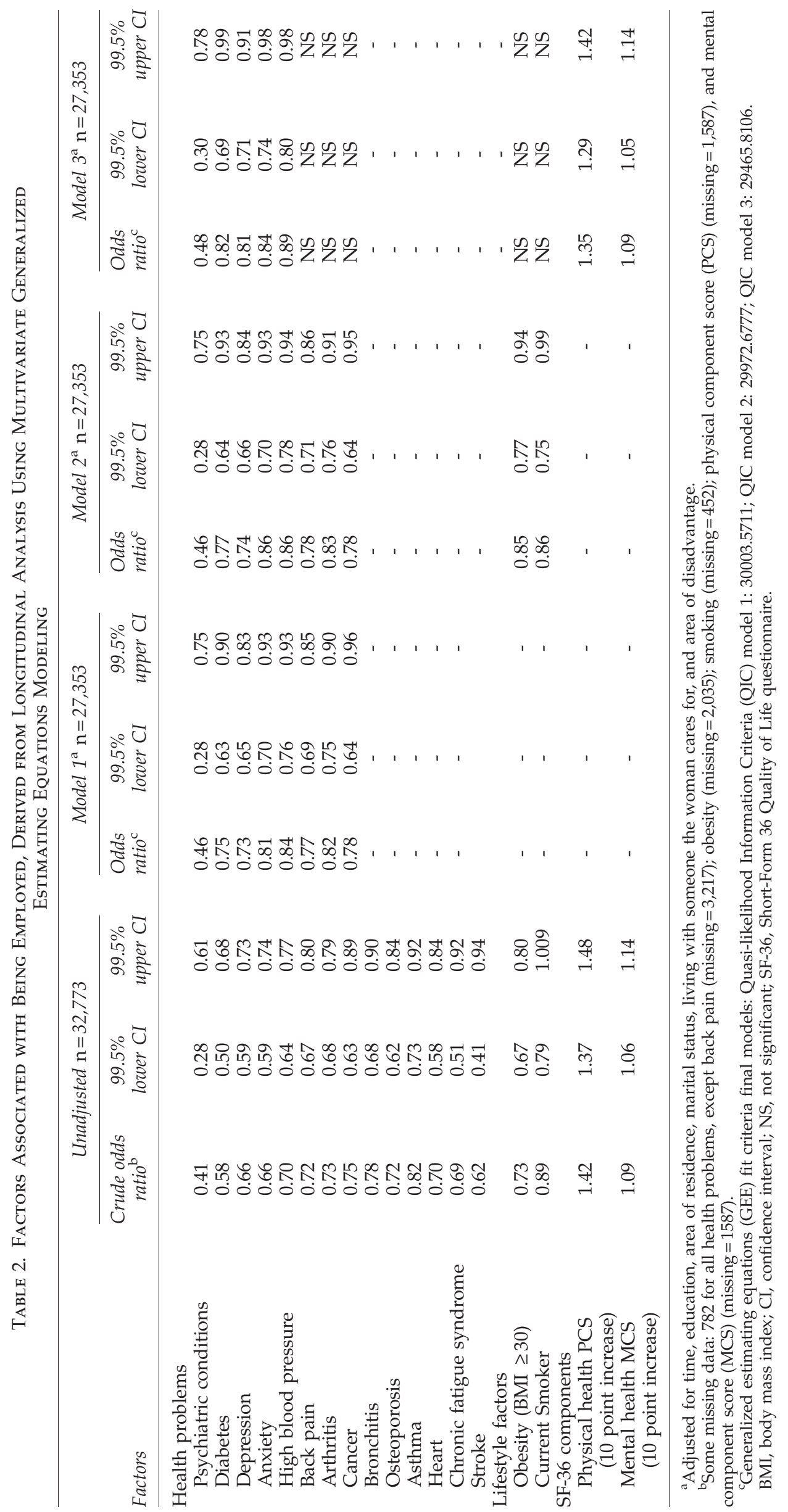


Whereas unadjusted ORs showed that all diseases are associated with employment among mature age women on their own, in real life, people have multiple conditions. Therefore, all conditions were put into one model to see which conditions remain associated with employment after adjustment for the relevant sociodemographic variables. Eight conditions remained associated with employment that could be split broadly into mental conditions (psychiatric conditions, depression, anxiety) and physical conditions (diabetes, high blood pressure, back pain, arthritis, and cancer). Across all models, psychiatric conditions remained having the strongest association with employment.

Important lifestyle factors, such as obesity and smoking, have an impact on such health conditions as diabetes, high blood pressure, and arthritis. It was, therefore, hypothesized that these two variables would alter the model significantly if added, but this was not the case. The associations between health conditions and employment became slightly weaker but did not change the model much, and the associations among obesity, smoking, and employment also remained significant. Women who were not employed were significantly more likely to be obese and to be current smokers, but this effect disappeared when quality of life was taken into account. This may suggest that the relationships between obesity and being a current smoker with employment are explained through how women perceive their quality of life. A U.S. study ${ }^{7}$ also found that obesity can impact on women's labor market decisions through impairment of bodily functions.

This study attempted to see which health problems have the strongest associations with women's employment status after adjusting for important variables and how women's own perception of their health changes the association of various diseases with their employment status. Two things can be interpreted from adding quality of life to the model. First, it appeared that several physical health conditions were no longer associated with employment: arthritis, back pain, and cancer. This suggests that these health problems appear to exert their effect on women's employment mainly through the effect of quality of life. It should be mentioned that the effect for cancer approached significance, so this should be interpreted with caution. Second, other health problems that remained significant in the model after adding quality of life appear to have an effect over and above quality of life. These effects could arise from a number of external factors that are beyond women's own personal control, including that employers are less likely to employ women with these conditions. Alternatively, women themselves may elect to give up work because of their condition. In other analyses, for instance, it has been found that women who have more health problems themselves are more likely to give up work to take on caring responsibilities. ${ }^{29}$

Over time, both employed and nonemployed women had improved mental health, but physical health stayed the same. The positive effect of aging on mental health has been shown in other studies. For example, the 1997 National Survey of Mental Health and Well-being found that women aged 55-59, 65-69, and 70-74 had significantly lower rates of mental disorders than those aged $45-49 .^{30}$ This finding is important because it appears that higher mental health scores are associated with employment among the women in this study. A study in Singapore found that working seniors had a better mental well-being and fewer depressive symptoms than did nonvolunteering seniors. ${ }^{31}$ Women who keep working often experience positive mental health benefits from working, possibly reflecting a higher self-esteem because of work status, a better social network, ${ }^{31}$ and a sense of purpose and contributing to society. However, all these issues require further investigation for this particular group to explore the deeper meaning of these findings.

\section{Application}

In cases, where companies, organizations, or policymakers wish to identify women at risk of leaving employment, it may be helpful to identify women with the following characteristics: health problems (including psychiatric conditions, depression, anxiety, diabetes, high blood pressure, back pain, arthritis, cancer) or women who are obese or current smokers or lower self-reported quality of life and address any issues that they may have to ensure they remained employed.

\section{Limitations and strengths}

A major strength of this study was the use of a large national representative sample of community-dwelling women nearing retirement age. Using this cohort of women allowed us to examine a population that is growing in size as our population ages and that, therefore, also forms part of our growing aging workforce. Strategies and instruments are needed to prolong working life for this important cohort. Keeping mature age women as healthy as possible is one way to prolong working life.

Several study limitations need to be considered when interpreting study results. First, a higher proportion of women who responded to S3,S4, and S5 were employed at S1, suggesting that a healthy cohort effect has taken place. This may underestimate the effect size of the ORs of health problems and their association with employment, particularly for diseases with high mortality or morbidity rates, causing women with these health problems to not take part in follow-up surveys. Second, the study did not take into account women's previous or current occupational level or severity of disease. Third, women who were on holidays during the study period may not have fallen into the employed category.

\section{Conclusions}

Women's ongoing participation in the workforce at older ages is affected by both sociodemographic and health factors, with single women and those from more disadvantaged areas being more likely to work, and those with caring responsibilities of people they live with and health conditions being less likely to work. Understanding these relationships could inform policies and guidelines for preventing declines in employment in mature age women. The impact of health conditions on women's ability and preparedness to continue working is an issue of concern both for governments that are striving to encourage workforce participation and for the financially disadvantaged women who need to work to maintain financial security in later life.

\section{Acknowledgments}

The research on which this article is based was conducted as part of the Australian Longitudinal Study on Women's Health, the University of Newcastle, and the University of 
Queensland. We are grateful to the Australian Government Department of Health and Ageing for funding and to the women who provided the survey data.

This work was supported by the Australian National Health and Medical Research Council via an Australian Research Training Fellowship Part-time (ID 511998) to S.W.P. The funding body played no role in the design, execution, analysis and interpretation of data, or writing of the study.

\section{Disclosure Statement}

No competing financial interests exist.

\section{References}

1. Australian Bureau of Statistics. 6238.0-Retirement and retirement intentions, Australia, July 2006 to Jun 2007. Canberra: Australian Bureau of Statistics, 2008.

2. Warner-Smith P, Powers J, Hampson A. Women's experiences of paid work and planning for retirement. Women's Health Australia. Report to the Office for Women, Department of Families, Community Services and Indigenous affairs. Canberra, 2008.

3. Australian Human Rights Commission. The gender gap in retirement savings. Available at www.hreoc.gov.au/sex discrimination/programs/gender_gap.html Accessed October 22, 2009.

4. Olsberg D. Women, superannuation and retirement: Grim prospects despite policy changes. Just Policy J Aust Soc Policy 2005;35:31-38.

5. Kelly S, Schofield DJ. The economic burden of chronic disease: Costs of illness beyond the health system. Presentation to The Treasury, Canberra, November 25, 2008. Source: Kelly (2008) based on HILDA Wave 6 (2006) data file. Sydney: University of Sydney, 2008.

6. Shultz KS, Morton KR, Weckerle JR. The influence of push and pull factors on voluntary and involuntary early retirees' retirement decision and adjustment. J Vocational Behav 1998;53:45-57.

7. Renna F, Nidhi T. Direct and indirect effects of obesity on U.S. labor market outcomes of older working age adults. Soc Sci Med 2010;71:405-413.

8. Kalwij A, Vermeulen F. Health and labour force participation of older people in Europe: What do objective health indicators add to the analysis? Health Econ 2008;17:619-638.

9. Gordon L, Lynch BM, Newman B. Transitions in work participation after a diagnosis of colorectal cancer. Aust NZ J Public Health 2008;32:569-574.

10. Ettner SL. The impact of "parent care" on female labor supply decisions. Demography 1995;32:63.

11. Gould R, Ilmarinen J, Jarvisalo J, Koskinen S. Dimensions of work ability. Summary and conclusions. In: Gould R, Ilmarinen J, Koskinen S, eds. Dimensions of work ability. Results of the Health 2000 Survey. Helsinki: Finish Centre for Pensions, The Social Insurance Institution, National Public Health Institute, Finnish Institute of Occupational Health, 2008:165-175.

12. Pit SW, Shrestha R, Schofield D, Passey M. Health problems and retirement due to ill-health among Australian retirees aged 45-64 years. Health Policy 2010;94:175-181.

13. Schofield DJ, Shrestha RN, Passey ME, Earnest A, Fletcher, S. Chronic disease and labour force participation among older Australians. Med J Aust 2008;189:447-450.

14. Zhang $\mathrm{XH}$, Zhao $\mathrm{XY}$, Harris A. Chronic diseases and labour force participation in Australia. J Health Econ 2009;28:91-108.

15. Adams J, Sibbritt D, Young AF. A longitudinal analysis of older Australian women's consultations with complemen- tary and alternative medicine (CAM) practitioners, 19962005. Age Ageing 2009;38:93-99.

16. Mein G, Martikainen P, Hemingway H, Stansfeld S, Marmot, M. Is retirement good or bad for mental and physical health functioning? Whitehall II longitudinal study of civil servants. J Epidemiol Community Health 2003;57:46-49.

17. van Solinge $H$. Health change in retirement: A longitudinal study among older workers in the Netherlands. Res Aging 2007;29:225-256.

18. Vijan S, Hayward RA, Langa KM. The impact of diabetes on workforce participation: Results from a national household sample. Health Serv Res 2004;39:1653-1669.

19. Houston DK, Cai J, Stevens J. Overweight and obesity in young and middle age and early retirement: The ARIC study. Obesity 2009;17:143-149.

20. Chatterji S, Kowal P, Mathers C, et al. The health of aging populations in China and India. Health Aff 2008;27:1052-1063.

21. Brown WJ, Bryson L, Byles JE, et al. Women's Health Australia: Recruitment for a national longitudinal cohort study. Women Health 1998;28:23-40.

22. Australian Institute of Health and Welfare (AIHW). Rural, regional and remote health: A guide to remoteness classifications. AIHW cat. No. PHE 53. Canberra: AIHW, 2004.

23. Australian Bureau of Statistics (ABS). 1996 census of population and housing. Socioeconomic indexes for areas. ABS Catalogue Number 2039.0. Canberra: ABS, 1998.

24. World Health Organization (WHO). Global database on body mass index. Available at apps.who.int/bmi/index .jsp?introPage = intro_3.html Accessed January 15, 2010.

25. Ware JE, Snow KK, Kosinski M, Gandek B. SF-36 Health survey: Manual and interpretation guide. Boston, MA: The Health Institute, New England Medical Center, 1993.

26. Ware J, Kosinski M, Keller S. SF-36 Physical and Mental Health Summary Scales: A users manual. Boston, Massachusetts: The Health Institute, New England Medical Center, 1994.

27. SAS Institute Inc. Longitudinal data analysis with discrete and continuous reponses course notes. Cary, NC: SAS Institute Inc, 2009.

28. Cai LX, Kalb G. Health status and labour force participation: Evidence from Australia. Health Econ 2006;15:241-261.

29. Berecki-Gisolf J, Lucke J, Hockey R, Dobson A. Transitions into informal caregiving and out of paid employment of women in their 50s. Soc Sci Med 2008;67:122-127.

30. Butterworth P, Gill SC, Rodgers B, Anstey KJ, Villamil E, Melzer D. Retirement and mental health: Analysis of the Australian National Survey of Mental Health and WellBeing. Soc Sci Med 2006;62:1179-1191.

31. Schwingel A, Niti MM, Tang C, et al. Continued work employment and volunteerism and mental well-being of older adults: Singapore longitudinal ageing studies. Age Ageing 2009;38:531-537.

Address correspondence to Sabrina W. Pit, Ph.D., M.Sc.

NHMRC Research Fellow

University Centre for Rural Health Northern Rivers School of Public Health

University of Sydney 61 Uralba Street

PO Box 3074

Lismore NSW 2480

Australia

E-mail: sabrina.pit@sydney.edu.au 